\title{
Divertimentum Ornithologicum
}

\section{Pedro Poitevin}

After Jorge Luis Borges's

Argumentum Ornithologicum.

\begin{abstract}
A synchrony of wings across the sky is quavering its feathered beats of flight. Their number is too high to count-I try to estimate it but I can't: the night is dark, the birds are black, my eyes are weak. Certainly less than $N$ but more than $k$, I tell myself, but then, in an oblique arrow of thought, I argue with dismay that if $k$ is too small, then $k+1$ can't be enough, and so, inductively, all of God's natural numbers fail-there's none determining how many birds I see. I entertain that He might not exist, but $N$ being hyperfinite I resist.
\end{abstract}

